OPEN ACCESS

Edited by:

Richard H. Gomer,

Texas A\&M University, United States

Reviewed by:

Alexander J. Szalai,

University of Alabama at Birmingham,

United States

Rachel Victoria Jimenez,

Moffitt Cancer Center, United States

*Correspondence:

Alok Agrawal

agrawal@etsu.edu

${ }^{\dagger}$ These authors have contributed equally to this work

Specialty section: This article was submitted to

Molecular Innate Immunity,

a section of the journal

Frontiers in Immunology

Received: 23 October 2020 Accepted: 03 December 2020

Published: 20 January 2021

Citation:

Ngwa DN, Singh SK and Agrawal A (2021) C-Reactive Protein-Based

Strategy to Reduce Antibiotic Dosing for the Treatment of

Pneumococcal Infection.

Front. Immunol. 11:620784. doi: 10.3389/fimmu.2020.620784

\section{C-Reactive Protein-Based Strategy to Reduce Antibiotic Dosing for the Treatment of Pneumococcal Infection}

\author{
Donald N. Ngwa ${ }^{\dagger}$, Sanjay K. Singh ${ }^{\dagger}$ and Alok Agrawal ${ }^{*}$ \\ Department of Biomedical Sciences, James H. Quillen College of Medicine, East Tennessee State University, Johnson City, \\ TN, United States
}

C-reactive protein (CRP) is a component of innate immunity. The concentration of CRP in serum increases in microbial infections including Streptococcus pneumoniae infection. Employing a mouse model of pneumococcal infection, it has been shown that passively administered human wild-type CRP protects mice against infection, provided that CRP is injected into mice within two hours of administering pneumococci. Engineered CRP (E-CRP) molecules have been reported recently; unlike wild-type CRP, passively administered E-CRP protected mice against infection even when E-CRP was injected into mice after twelve hours of administering pneumococci. The current study was aimed at comparing the protective capacity of E-CRP with that of an antibiotic clarithromycin. We established a mouse model of pneumococcal infection in which both E-CRP and clarithromycin, when used alone, provided minimal but equal protection against infection. In this model, the combination of E-CRP and clarithromycin drastically reduced bacteremia and increased survival of mice when compared to the protective effects of either E-CRP or clarithromycin alone. E-CRP was more effective in reducing bacteremia in mice treated with clarithromycin than in untreated mice. Also, there was $90 \%$ reduction in antibiotic dosing by including $\mathrm{E}-\mathrm{CRP}$ in the antibiotic-treatment for maximal protection of infected mice. These findings provide an example of cooperation between the innate immune system and molecules that prevent multiplication of bacteria, and that should be exploited to develop novel combination therapies for infections against multidrug-resistant pneumococci. The reduction in antibiotic dosing by including E-CRP in the combination therapy might also resolve the problem of developing antibiotic resistance.

Keywords: C-reactive protein, clarithromycin, pneumococcal infection, Streptococcus pneumoniae, combination therapy

\section{INTRODUCTION}

C-reactive protein (CRP) is a critical host defense molecule of the innate immune system $(1,2)$. CRP binds to cells and molecules, host or foreign, which have accessible phosphocholine (PCh) moieties $(3,4)$. One example of CRP-ligands is pneumococcal C-polysaccharide found on the surface of Streptococcus pneumoniae (5). Once bound to a PCh-bearing ligand, CRP activates the complement 
system in both human and murine sera to damage and, if possible, eliminate the ligand (6-9). Experiments employing human CRP transgenic mice, CRP-deficient mice, and normal mice in which human wild-type CRP (WT CRP) was passively administered have all revealed that CRP is protective against pneumococcal infection $(2,10-15)$. It has also been shown that the anti-pneumococcal activity of CRP in vivo is due to the ability of ligand-complexed CRP to activate the complement system (9, 16-18). However, WT CRP was found to be protective only when given to mice within $2 \mathrm{~h}$ of administering pneumococci in the mouse model of infection in which WT CRP is passively administered (16).

CRP is a pentameric molecule comprised of five identical subunits $(19,20)$. Recently, two types of engineered pentameric CRP (E-CRP), E-CRP-1, and E-CRP-2, generated by oligonucleotide-directed site-specific mutagenesis of WT CRP cDNA, have been reported (21). In E-CRP-1, four amino acid residues were mutated (E42Q/F66A/T76Y/E81A). In E-CRP-2, two amino acid residues were mutated (Y40F/E42Q). $\mathrm{Tyr}^{40}$ and $\mathrm{Glu}^{42}$ are present in the intrinsically disordered region of CRP. $\mathrm{Glu}^{42}$ is also a part of the inter-subunit contact region. Phe ${ }^{66}$, $\mathrm{Thr}^{76}$ and Glu ${ }^{81}$ form the PCh-binding site of CRP $(19,20)$. ECRP-1 does not bind to PCh while E-CRP-2, like WT CRP, binds to PCh. Both E-CRP-1 and E-CRP-2 bind to complement inhibitor factor $\mathrm{H}$ recruited by pneumococci on their surface in mouse circulation; WT CRP does not bind to immobilized factor $\mathrm{H}$ (22-25). Unlike passively administered WT CRP, both ECRP-1 and E-CRP-2 protected mice against infection even when E-CRP was administered $12 \mathrm{~h}$ after administering pneumococci, indicating that a conformationally altered form of CRP that can bind to immobilized factor $\mathrm{H}$ is required for CRP-mediated protection of mice against late-stage pneumococcal infection (1, 21). Accordingly, it was hypothesized that in individuals in whom the conformation of CRP remains unchanged, perhaps due to inappropriate inflammatory conditions around CRP, CRP is not fully functional during infection (21). It was proposed that the use of E-CRP might be beneficial for treatment of infections against antibiotic-resistant pneumococci (21).

Antibiotics are commonly used to treat pneumococcal infection in humans (26). The aim of this study was to directly compare the protective effects (increase in survival and decrease in bacteremia) of E-CRP and antibiotics. Since the antibiotic clarithromycin has been used previously in mouse models of pneumococcal infection and was found to be protective when administered into mice later during the infection (27), clarithromycin was selected for the current study. Both E-CRP1 and E-CRP-2 were included in the study to compare the protective effects with that of clarithromycin. A mouse model of pneumococcal infection was employed in which E-CRP-1, ECRP-2, and clarithromycin, when used singly, provided minimal but equal protection against infection. This model was suitable to investigate the protection against infection when E-CRP-1 or E-

Abbreviations: CRP, C-reactive protein; E-CRP-1, engineered CRP mutant E42Q/ F66A/T76Y/E81A; E-CRP-2, engineered CRP mutant Y40F/E42Q; moCRP, endogenous mouse CRP; PCh, phosphocholine; WT CRP, native wild-type CRP purified from discarded human body fluids.
CRP-2 and clarithromycin were combined for the treatment of mice. The results of the experiments indicate that E-CRP is more effective in reducing bacteremia in mice when used in the presence of clarithromycin.

\section{MATERIALS AND METHODS}

\section{Preparation of CRP}

The cDNAs for E-CRP-1 (E42Q/F66A/T76Y/E81A mutant CRP) and E-CRP-2 (Y40F/E42Q mutant CRP) were constructed and expressed in $\mathrm{CHO}$ cells using the ExpiCHO Expression System (Thermo Fisher Scientific), as described earlier (21). Purification of E-CRP-1 from cell culture supernatants involved $\mathrm{Ca}^{2+}$-dependent affinity chromatography on a phosphoethanolamine-conjugated Sepharose column, followed by ion-exchange chromatography on a MonoQ column and gel filtration on a Superose12 column, as described earlier (14). E-CRP-2 was purified by $\mathrm{Ca}^{2+}$. dependent affinity chromatography on a PCh-conjugated Sepharose column, followed by ion-exchange chromatography on a MonoQ column and gel filtration on a Superose 12 column, as described earlier (8). Native WT CRP was purified from discarded human pleural fluid by $\mathrm{Ca}^{2+}$-dependent affinity chromatography on a PCh-conjugated Sepharose column, followed by ion-exchange chromatography on a MonoQ column and gel filtration on a Superose 12 column, as described earlier (8), and was used throughout this study. Purified CRP was dialyzed against $10 \mathrm{mM}$ Tris- $\mathrm{HCl}, \mathrm{pH} 7.2$, containing $150 \mathrm{mM} \mathrm{NaCl}$ and $2 \mathrm{mM} \mathrm{CaCl}_{2}$, and was subsequently treated with Detoxi-Gel Endotoxin Removing Gel (Thermo Fisher Scientific) according to manufacturer's instructions. The concentration of endotoxin in CRP preparations was determined by using the Limulus Amebocyte Lysate kit QCL-1000 (Lonza). Purified CRP was stored at $4^{\circ} \mathrm{C}$ and used within a week for mouse protection experiments.

\section{Pneumococci}

Streptococcus pneumoniae type 3, strain WU2, was obtained as a gift from Dr. David Briles (University of Alabama at Birmingham, Birmingham, AL, USA). Pneumococci were made virulent by sequential i.v. passages in mice and were stored in aliquots at $-80^{\circ} \mathrm{C}$, as described previously $(14,15)$. For each experiment, a separate aliquot of pneumococci was thawed and cultured, as described previously $(14,15)$. Cultured pneumococci were resuspended in normal saline at a concentration of $3.5 \times 10^{8} \mathrm{cfu} / \mathrm{ml}$ based on the absorbance of the resuspension at $600 \mathrm{~nm}\left(\mathrm{~A}_{600}=1.00=1.2 \times 10^{9} \mathrm{cfu} / \mathrm{ml}\right)$. Within $2 \mathrm{~h}, 100 \mu \mathrm{l}\left(3.5 \times 10^{7} \mathrm{cfu}\right)$ of pneumococci suspension was injected into each mouse, as reported previously $(14,15,21)$. The concentration of pneumococci was confirmed next day by plating on sheep blood agar plates.

\section{Mice}

Male C57BL/6J mice (Jackson Laboratories) were brought up and maintained according to protocols approved by the 
University Committee on Animal Care. Mice were 8-10 weeks old when used in experiments.

\section{Determination of the Experimental Dose of Clarithromycin}

The antibiotic clarithromycin (Santa Cruz Biotechnology, sc205634) was reconstituted in acetone at a concentration of 50 $\mathrm{mg} / \mathrm{ml}$ and stored at $4^{\circ} \mathrm{C}$ for a maximum of 5 days. To determine the experimental dose for in vivo experiments, clarithromycin $(50 \mathrm{mg} / \mathrm{ml})$ was diluted in acetone at $40,4.0,0.4$ and $0.04 \mathrm{mg} / \mathrm{ml}$, and $50 \mu \mathrm{l}$ of each concentration was injected i.v. into mouse, four times, at 12, 36, 60 and $84 \mathrm{~h}$ after the administration of pneumococci. Thus, the final amount of clarithromycin in each group of mice was 2, 0.2, 0.02 and $0.002 \mathrm{mg}$ per mouse per injection. As shown in Figure 1, it was clear that a dose of 0.02 mg clarithromycin per mouse per injection was most suitable to evaluate the effects of the combination of clarithromycin and ECRP on the protection of mice against infection. The dose of 0.02 $\mathrm{mg}$ of clarithromycin resulted in a survival curve which fell in the middle so that a shift of the curve, either above or below, could be observed when E-CRP is added.

\section{Mouse Protection Experiments}

Two separate protection experiments were performed using 25 $\mu \mathrm{g}$ of purified WT CRP, E-CRP-1 and E-CRP-2, and $3.5 \times 10^{7}$ cfu of pneumococci, as described earlier $(14,15,21)$. The average amount of endotoxin in $25 \mu \mathrm{g}$ of all CRP preparations was $1.2 \pm 1.1$ endotoxin units. Mice were first injected i.v. with $3.5 \times$ $10^{7} \mathrm{cfu}$ of pneumococci. The actual number of pneumococci injected, based on the plating results obtained on the next day, was $3.55 \pm 0.44 \times 10^{7} \mathrm{cfu}$. Mice were injected i.v. with either WT CRP, E-CRP-1 or E-CRP-2, $12 \mathrm{~h}$ after the administration of pneumococci. Since clarithromycin is soluble in nornal saline at $0.2 \mathrm{mg} / \mathrm{ml}$, stock clarithromycin $(50 \mathrm{mg} / \mathrm{ml}$ in acetone) was diluted in normal saline to a final concentration of $0.2 \mathrm{mg} / \mathrm{ml}$, and $100 \mu \mathrm{l}$ was injected i.v. per mouse at $13,36,60$ and $84 \mathrm{~h}$ after the administration of pneumococci, to achieve a final dose of $0.02 \mathrm{mg}$ of clarithromycin per mouse per injection. Survival of mice was recorded three times per day for 7 days. To determine bacteremia $(\mathrm{cfu} / \mathrm{ml})$ in the surviving mice, blood was collected daily for 5 days from the tip of the tail vein, diluted in normal saline, and plated on sheep blood agar for colony counting. The bacteremia value for dead mice was recorded as $10^{9} \mathrm{cfu} / \mathrm{ml}$ because mice died when the bacteremia exceeded $10^{8} \mathrm{cfu} / \mathrm{ml}$.

\section{Statistical Analysis}

Survival curves were generated using the GraphPad Prism 4 software. To determine $p$-values for the differences in the survival curves among various groups, the survival curves were compared using the software's Logrank (Mantel-Cox) test. The scatter plots of the bacteremia data and the median bacteremia value for each group were generated using the GraphPad Prism 4 software. Bacteremia values of $0-100$ were plotted as 100 and bacteremia values of $>10^{8}$ were plotted as $10^{9}$. To determine $p$-values for the differences in bacteremia among various groups at each time point, scatter plots were compared using the software's MannWhitney test. The software's Mann-Whitney test included all the dots in the scatter plots and not just the median values for each time point.

\section{RESULTS}

\section{Anti-Pneumococcal Effects of E-CRP-1, Clarithromycin, and Their Combination}

As shown in Figure 2, and as reported previously (21), E-CRP-1 increased significantly the median survival time (MST, the time taken for the death of $50 \%$ of mice) of mice infected with pneumococci. The MST for mice injected with bacteria alone (group A) was $60 \mathrm{~h}$ while the MST for mice injected with E-CRP1 (group B) was $84 \mathrm{~h}$. Similarly, clarithromycin also significantly increased the survival of mice infected with pneumococci; the MST for mice treated with clarithromycin (group C) was $96 \mathrm{~h}$. The increase in the MST for mice treated with either E-CRP-1 or clarithromycin were not significantly different from each other. In this mouse model of pneumococcal infection, it has been reported previously that WT CRP does not increase the MST if mice received WT CRP $12 \mathrm{~h}$ after receiving pneumococci (21). The protection in response to the combination of WT CRP and

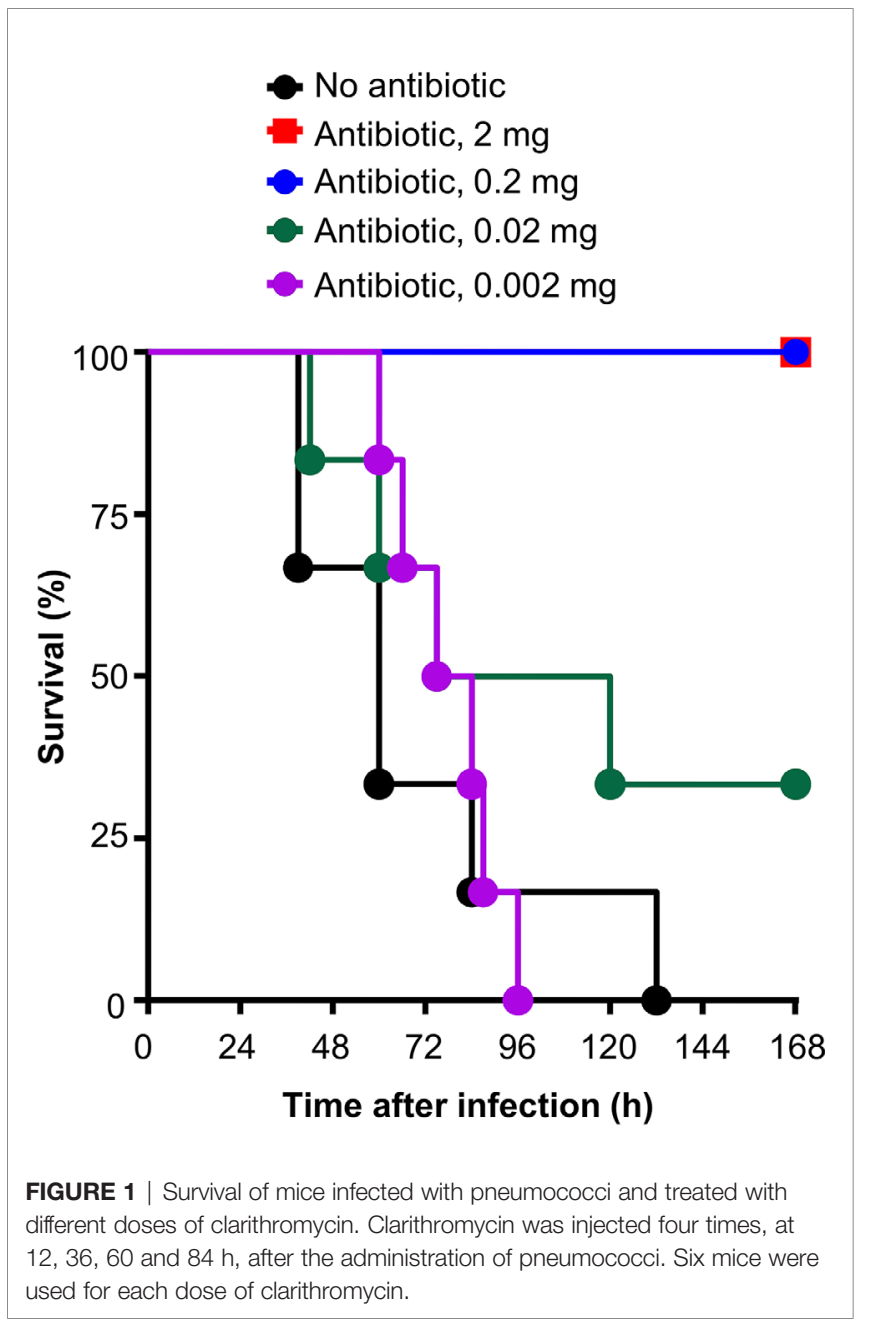


clarithromycin (group D) was similar to that of clarithromycin alone. The MST for mice treated with the combination of WT CRP and clarithromycin was $84 \mathrm{~h}$ similar to the MST for mice treated with clarithromycin alone (group C). In contrast to WT CRP, the combination of E-CRP-1 and clarithromycin significantly increased the survival of infected mice (group E). The MST for mice treated with both E-CRP-1 and clarithromycin was significantly different than the MST for mice treated with either agent alone. The MST for mice treated with E-CRP-1 and clarithromycin could not be calculated since $\sim 90 \%$ of mice survived till the end of the experiment. In all other groups, $>75 \%$ mice died within 5 days. The combination of ECRP-1 and $0.02 \mathrm{mg}$ clarithromycin provided the same protection (Figure 2) in terms of survival of mice as was seen with $0.2 \mathrm{mg}$ of clarithromycin when used alone (Figure 1). Thus, there was $90 \%$

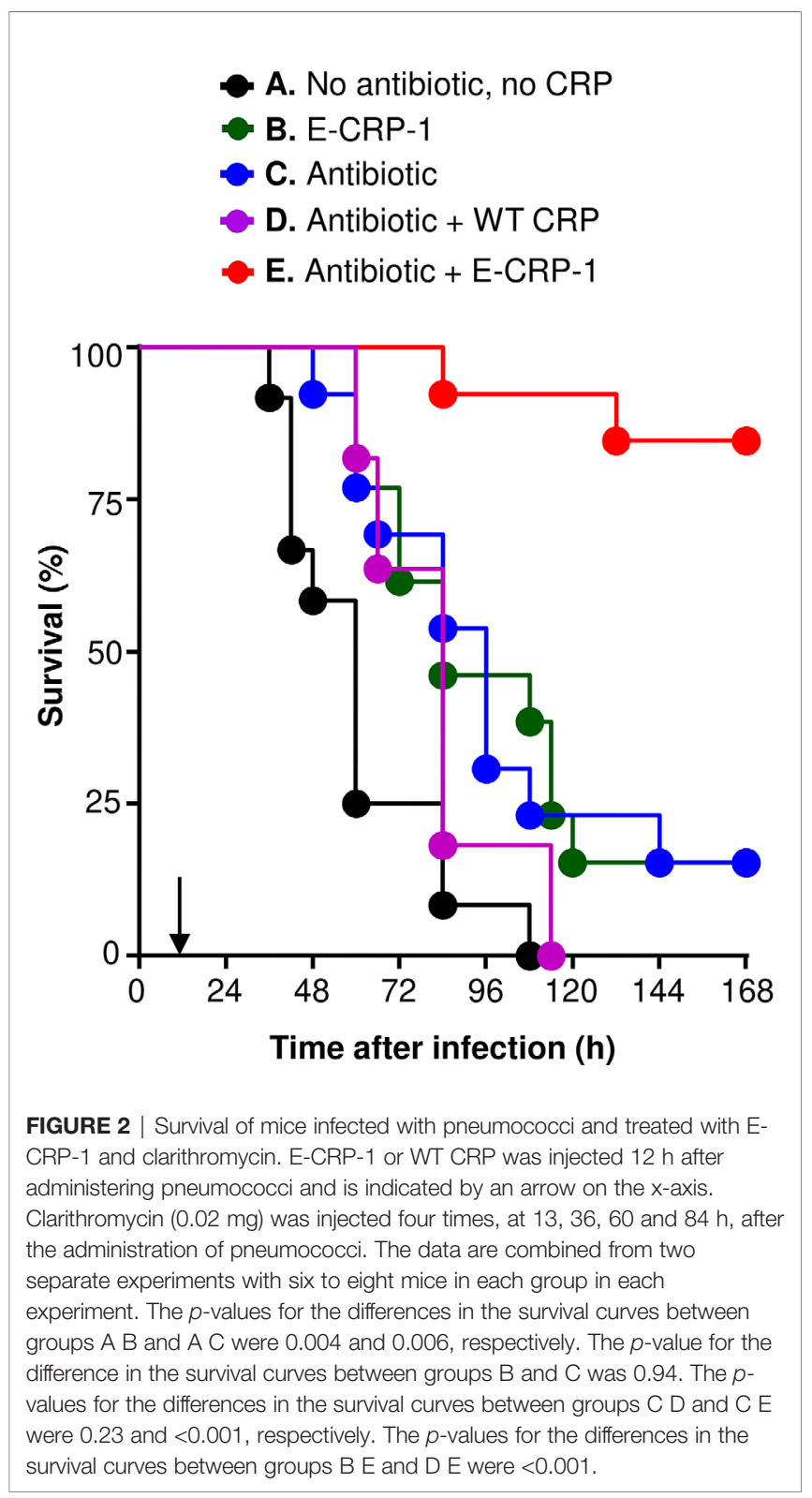

reduction in the dose of clarithromycin when used in combination with E-CRP-1.

The protective effects of E-CRP-1 (group B) and clarithromycin (group C) on the survival of mice, when used alone, were due to significant decrease in bacteremia (Figures 3A, B). E-CRP-1, as reported previously (21), and clarithromycin, both significantly decreased bacteremia. The decrease in bacteremia by E-CRP-1 and by clarithromycin were not significantly different from each other. Consistent with the survival data, the combination of WT CRP and clarithromycin (group D) did not significantly affect the protective ability of clarithromycin in terms of decreasing bacteremia. The dramatic increase in the survival of infected mice by the combination of E-CRP-1 and clarithromycin (group E) was due to the drastic decrease in bacteremia. The decrease in bacteremia in mice treated with both agents was significantly different from the decrease in bacteremia when mice were treated with either of the two agents alone. Bacteremia did not rise beyond $10^{4} \mathrm{cfu} / \mathrm{ml}$ in mice treated with both E-CRP-1 and clarithromycin. The median bacteremia was maintained at the reduced level from the beginning to the end of the experiment.

Overall, based on the statistical analyses of the survival curves (Figure 2) and of the scatter plots for bacteremia (Figure 3A), highly significant differences were found between the groups of mice treated with both E-CRP-1 and clarithromycin and the groups of mice treated with either agent alone. The antipneumococcal effects of E-CRP-1 were enhanced in the presence of low-dose clarithromycin. Combining E-CRP-1 with clarithromycin in the treatment of pneumococcal infection in this mouse model reduced the dose of clarithromycin by $90 \%$.

\section{Anti-Pneumococcal Effects of E-CRP-2, Clarithromycin, and Their Combination}

As shown in Figure 4, and as reported previously (21), E-CRP-2 increased significantly the MST of mice infected with pneumococci. The MST for mice injected with bacteria alone (group A) was $54 \mathrm{~h}$ while the MST for mice injected with E-CRP2 (group B) was $132 \mathrm{~h}$. Clarithromycin also significantly increased the survival of mice infected with pneumococci; the MST for mice treated with clarithromycin (group C) was $108 \mathrm{~h}$. The increase in the MST for mice treated with either E-CRP-2 or clarithromycin were not significantly different from each other. The combination of E-CRP-2 and clarithromycin significantly increased the survival of infected mice (group D). The MST for mice treated with both E-CRP-2 and clarithromycin was significantly different than the MST for mice treated with either agent alone. The MST for mice treated with the combination of E-CRP-2 and clarithromycin could not be calculated since $\sim 80 \%$ of mice survived till the end of the experiment. In all other groups, $>50 \%$ mice died in 5 days. The combination of E-CRP-2 and $0.02 \mathrm{mg}$ clarithromycin provided the same protection (Figure 4) in terms of survival of mice as was seen with $0.2 \mathrm{mg}$ of clarithromycin when used alone (Figure 1). Thus, like E-CRP-1, there was $90 \%$ reduction in the dose of clarithromycin when combined with E-CRP-2.

The protective effects of E-CRP-2 (group B) and clarithromycin (group C) on the survival of mice, when used 

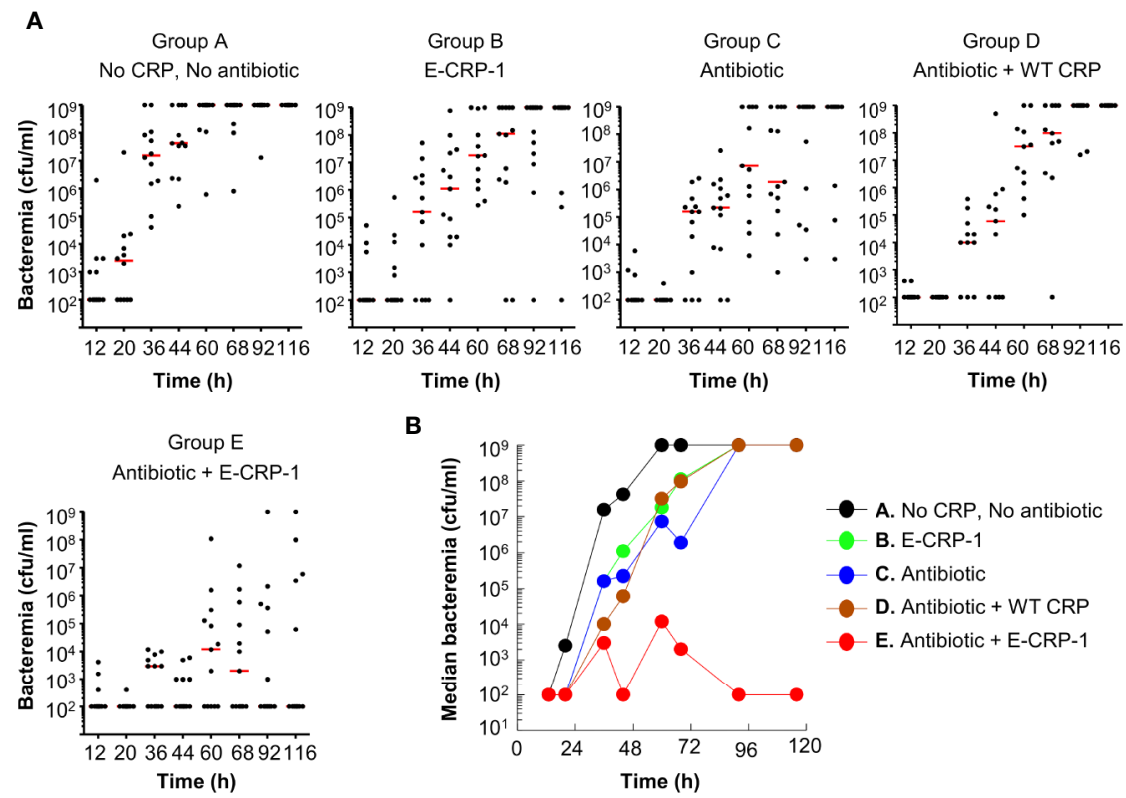

B

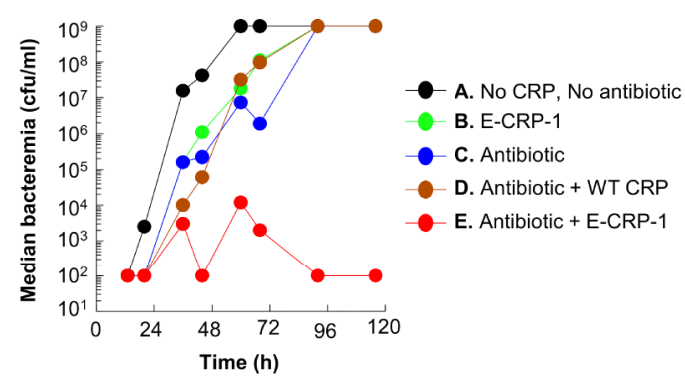

FIGURE 3 | Bacteremia in mice infected with pneumococci and treated with E-CRP-1 and clarithromycin. Blood was collected from each surviving mouse shown in Figure 2. (A) Scatter plots of the bacteremia data. The horizontal red line in each group of mice represents median bacteremia. (B) The median bacteremia values, derived from (A) For 36-92 $\mathrm{h}$, the $p$-value for the difference between groups A and B was $<0.05$. For 20-68 $\mathrm{h}$, the $p$-value for the difference between groups $\mathrm{A}$ and $C$ was $<0.05$. For all time points, the $p$-values for the differences between groups $B C$ and $C D$ were $>0.05$. For $36-116 h$, the $p$-values for the differences between groups $C E, B$ E, and D E were $<0.05$, with most significant difference $(p<0.005)$ between $44-92 \mathrm{~h}$.

alone, were due to significant decrease in bacteremia (Figures 5A, B). E-CRP-2, as reported previously (21), and clarithromycin, both significantly decreased bacteremia. The decrease in bacteremia by E-CRP-2 and by clarithromycin were not significantly different from each other. The dramatic increase in the survival of infected mice by the combination of E-CRP-2 and clarithromycin (group D) was due to the drastic decrease in bacteremia. The decrease in bacteremia in mice treated with both agents was significantly different from the decrease in bacteremia when mice were treated with either of the two agents alone. Bacteremia did not rise beyond $10^{5} \mathrm{cfu} / \mathrm{ml}$ in mice treated with both E-CRP-2 and clarithromycin. The median bacteremia was maintained at the reduced level from the beginning to the end of the experiment.

Overall, based on the statistical analyses of the survival curves (Figure 4) and of the scatter plots for bacteremia (Figure 5A), highly significant differences were found between the groups of mice treated with the combination of E-CRP-2 and clarithromycin and the groups of mice treated with either agent alone. The antipneumococcal effects of E-CRP-2 were enhanced in the presence of low-dose clarithromycin. Combining E-CRP-2 with clarithromycin in the treatment of pneumococcal infection in this mouse model reduced the dose of clarithromycin by $90 \%$.

\section{DISCUSSION}

E-CRP molecules capable of binding to factor $\mathrm{H}$ recruited on the surface of pneumococci have been shown to protect mice against late-stage pneumococcal infection (21). Antibiotics protect against pneumococcal infection too (27). The aim of this study was to compare the protective effects of E-CRP with that of an antibiotic clarithromycin employing the same animal model. Our major findings were: 1. Both E-CRP-1 and E-CRP-2, two different molecules capable of binding to factor $\mathrm{H}$ recruited on the surface of pneumococci, protected and acted synergistically with clarithromycin to drastically reduce bacteremia and enhance the survival of mice with late-stage pneumococcal infection. 2 . The combination of either E-CRP-1 or E-CRP-2 and $0.02 \mathrm{mg}$ clarithromycin provided the same protection as was seen with $0.2 \mathrm{mg}$ of clarithromycin when used alone. There was $90 \%$ reduction in the dose of clarithromycin when E-CRP was combined with clarithromycin for the treatment of infected mice. WT CRP did not do so.

Both E-CRP and clarithromycin decrease bacteremia, but via different mechanisms. E-CRP-mediated decrease in bacteremia is due to the activation of the complement system component of innate immunity. Clarithromycin is a macrolide antibiotic that has bacteriostatic action against gram-positive bacteria and some gram-negative bacteria including anaerobes. Clarithromycin is believed to function by binding to the ribosome within the microorganism and inhibiting protein synthesis, and thus inhibiting bacterial growth (26-29). A possible explanation for the synergy between E-CRP and clarithromycin is that the binding of E-CRP to factor $\mathrm{H}$, and perhaps also to other recruited complement inhibitor proteins on pneumococci (21), and subsequent attack by the complement system are more efficient when pneumococci are static; and a low-dose 


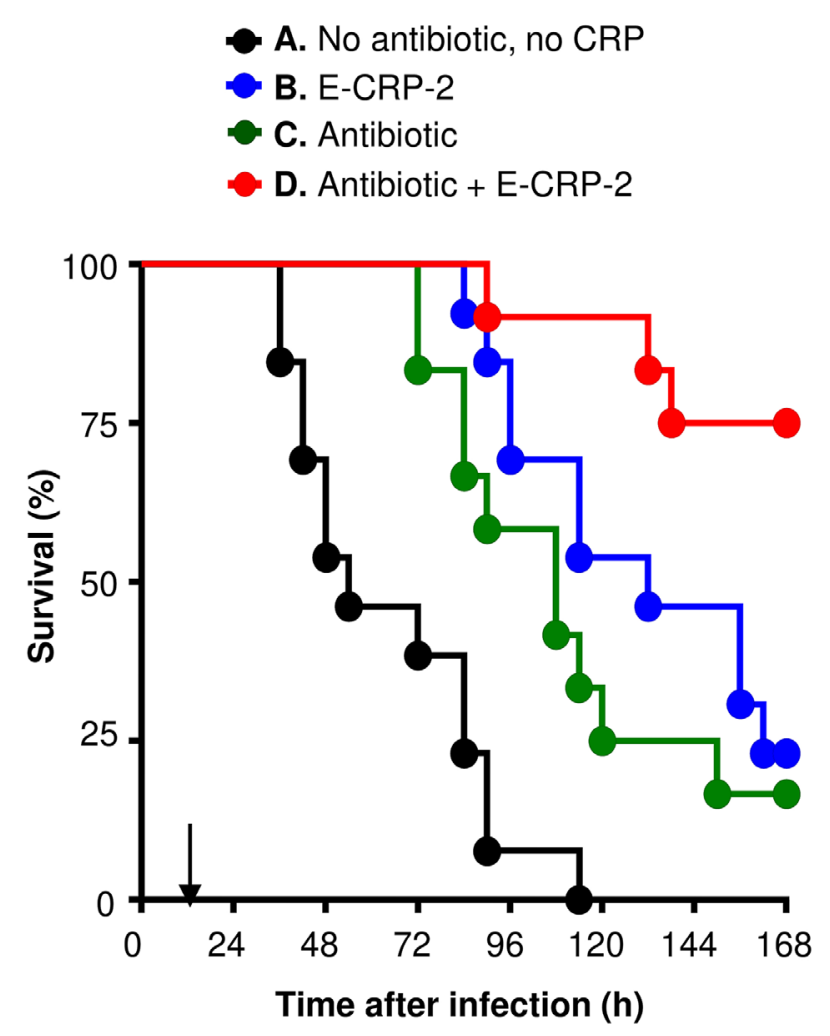

FIGURE 4 | Survival of mice infected with pneumococci and treated with ECRP-2 and clarithromycin. E-CRP-2 was injected $12 \mathrm{~h}$ after administering pneumococci and is indicated by an arrow on the $\mathrm{x}$-axis. Clarithromycin (0.02 mg) was injected four times, at 13,36, 60 and $84 \mathrm{~h}$, after the administration of pneumococci. The data are combined from two separate experiments with six to eight mice in each group in each experiment. The $p$-values for the differences in the survival curves between groups A B and A C were $<0.001$ and 0.002 , respectively. The $p$-value for the difference in the survival curves between groups $\mathrm{B}$ and $\mathrm{C}$ was 0.25 . The $p$-values for the differences in the survival curves between groups B D and C D were 0.01 and 0.002 , respectively.

clarithromycin treatment is sufficient to do that. In addition to the bacteriostatic action of clarithromycin, an increasing body of evidence suggests that clarithromycin possesses considerable anti-inflammatory and immunomodulatory properties, such as macrophage activation and inhibition of neutrophilic inflammation $(26,30-32)$. However, it is not clear whether the anti-inflammatory and immunomodulatory properties of clarithromycin participated in the synergy between clarithromycin and E-CRP in protection against infection. Nevertheless, our data provide a proof of concept that there is cooperation between E-CRP and clarithromycin in reducing bacteremia.

A single dose of E-CRP $(25 \mu \mathrm{g})$ combined with a tiny amount of clarithromycin $(0.02 \mathrm{mg})$ was the best prescription among all others in this study and in a previously published study (21) for nearly complete protection of our experimental mice. Neither ECRP $(25 \mu \mathrm{g})$ nor clarithromycin $(0.02 \mathrm{mg})$ could do it singly, indicating a previously unknown pathway through which the innate immune system responds to antibiotic treatment. The synergy between various CRP species and clarithromycin in reducing bacteremia is just another example of cooperation between a molecule of the innate immune system and antibiotics. It has been reported previously that the classical complement pathway-mediated immunity against antibioticresistant pneumococci was enhanced in the presence of subinhibitory concentrations of antibiotics cefditoren and ceftriaxone. The binding of CRP to pneumococci was also enhanced in the presence of serum plus either cefditoren or ceftriaxone. Complement activation was also enhanced in the presence of specific anti-pneumococcal antibodies and subinhibitory concentrations of antibiotics such as cefditoren, ceftriaxone and amoxicillin $(33,34)$. It has been suggested that using antibiotics to enhance complement activation might help reduce the impact of antibiotic resistance in pneumococcal infection $(33,34)$. The cooperation mechanisms between the molecules of the innate immune system and antibiotics should be exploited to develop novel combination therapies to treat infections with antibiotic-resistant pneumococci.

Combination therapies using antimicrobials with different mechanisms of action are used to treat infections against antibiotic-resistant pneumococci and, at the same time, are formulated to prevent the spread of the resistance (35-41). Combination therapies have been shown not only to be more effective against antibiotic-resistant bacteria but also significantly reduce any risk of bacteria developing resistance as seen in monotherapy. The power of E-CRP to reduce antibiotic dosing could be significant and might further assist in these goals to prevent emergence of antibiotic-resistant pneumococci. Usually, combination therapies involve low doses of two antibiotics from different classes. It has been suggested that antibiotic-antibiotic combination therapy may reduce and slow the development of antibiotic resistance. Eliminating one antibiotic from the combination altogether and substituting it with E-CRP should then be, in principle, more effective in reducing and slowing the development of antibiotic resistance. This strategy is similar to antibiotic-non-antibiotic combination therapies, such as adjuvant-antibiotic therapy, where one of the two antibiotics is substituted with an adjuvant with the goal to prevent the development of antibiotic resistance (35-41). We propose that E-CRP should be considered for inclusion in combination therapies. The ability of E-CRP to drastically reduce bacteremia even with a fraction of the normal dose of clarithromycin might contribute further to prevent the development and spread of antibiotic resistance. Our data suggest that, by adding E-CRP to E-CRP-antibiotic combination therapy, the dose of the remaining antibiotic can be kept low.

We conclude that the efficiency of the innate immune system is enhanced in the presence of antibiotics. Our findings provide another example of cooperation between the innate immune system and molecules that prevent multiplication of bacteria, and that should be exploited to develop novel combination therapies for infections against antibiotic-resistant pneumococci. The reduction in antibiotic 
A
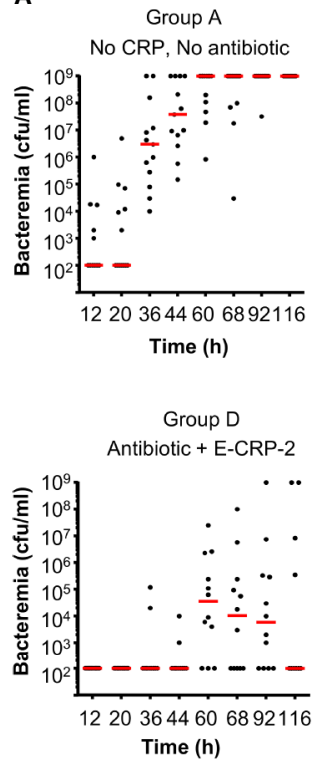

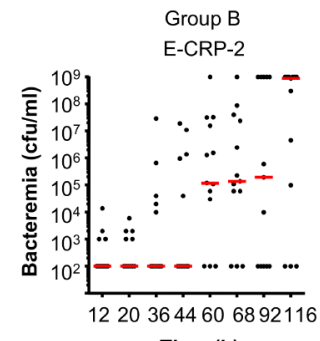

Time (h)

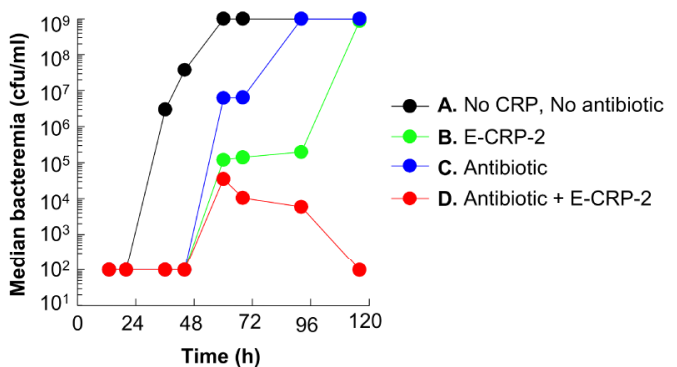

FIGURE 5 | Bacteremia in mice infected with pneumococci and treated with E-CRP-2 and clarithromycin. Blood was collected from each surviving mouse shown in Figure 4. (A) Scatter plots of the bacteremia data. The horizontal red line in each group of mice represents median bacteremia. (B) The median bacteremia values, derived from (A) For $36-116 \mathrm{~h}$, the $p$-value for the difference between groups $\mathrm{A}$ and $\mathrm{B}$ was $<0.005$. The $p$-values for the difference between groups $\mathrm{A}$ and $\mathrm{C}$ was $<0.005$ and $<0.05$ for $44-68 \mathrm{~h}$ and $92-116 \mathrm{~h}$, respectively. For all time points, the $p$-values for the differences between groups B $\mathrm{C}$ and $\mathrm{B} \mathrm{D}$ were $>0.05$. For 60 to $116 \mathrm{~h}$, the $p$-value for the difference between groups $\mathrm{C}$ and $\mathrm{D}$ was $<0.05$.

dosing by the strategy to include E-CRP in the combination therapy using antibiotics might also resolve the problem of developing and spreading antibiotic resistance.

\section{DATA AVAILABILITY STATEMENT}

The original contributions presented in the study are included in the article/supplementary materials, further inquiries can be directed to the corresponding author.

\section{ETHICS STATEMENT}

The animal study was reviewed and approved by University Committee on Animal Care, ETSU.

\section{REFERENCES}

1. Ngwa DN, Agrawal A. Structure-function relationships of C-reactive protein in bacterial infection. Front Immunol (2019) 10:166. doi: 10.3389/ fimmu.2019.00166

2. Simons JP, Loeffler JM, Al-Shawi R, Ellmerich S, Hutchinson WL, Tennent $\mathrm{GA}$, et al. C-reactive protein is essential for innate resistance to pneumococcal infection. Immunology (2014) 142:414-20. doi: 10.1111/imm.12266

3. Volanakis JE, Kaplan MH. Specificity of C-reactive protein for choline phosphate residues of pneumococcal C-polysaccharide. Proc Soc Exp Biol Med (1971) 136:612-4. doi: 10.3181/00379727-136-35323

4. Agrawal A. CRP after 2004. Mol Immunol (2005) 42:927-30. doi: 10.1016/ j.molimm.2004.09.028

\section{AUTHOR CONTRIBUTIONS}

DN and SS performed the experiments. AA conceived and designed the experiments. DN, SS, and AA analyzed the data. AA wrote the manuscript with input from DN. All authors contributed to the article and approved the submitted version.

\section{FUNDING}

This work was supported by the National Institutes of Health grants AR068787, AI117730. and AI151561.

5. Liu T-Y, Gotschlich EC. The chemical composition of pneumococcal C-polysaccharide. J Biol Chem (1963) 238:1928-34.

6. Kaplan $\mathrm{MH}$, Volanakis JE. Interaction of C-reactive protein complexes with the complement system. I. Consumption of human complement associated with the reaction of C-reactive protein with pneumococcal C-polysaccharide and with the choline phosphatides, lecithin, and sphingomyelin. J Immunol (1974) 112:2135-47.

7. Volanakis JE. Complement activation by C-reactive protein complexes. Ann N Y Acad Sci (1982) 389:235-50. doi: 10.1111/j.1749-6632.1982.tb22140.x

8. Suresh MV, Singh SK, Ferguson DAJr, Agrawal A. Role of the property of C-reactive protein to activate the classical pathway of complement in protecting mice from pneumococcal infection. J Immunol (2006) 176:436974. doi: 10.4049/jimmunol.176.7.4369 
9. Singh SK, Ngwa DN, Agrawal A. Complement activation by C-reactive protein is critical for protection of mice against pneumococcal infection. Front Immunol (2020) 11:1812. doi: 10.3389/fimmu.2020.01812

10. Szalai AJ, Briles DE, Volanakis JE. Human C-reactive protein is protective against fatal Streptococcus pneumoniae infection in transgenic mice. J Immunol (1995) 155:2557-63.

11. Yother J, Volanakis JE, Briles DE. Human C-reactive protein is protective against fatal Streptococcus pneumoniae infection in mice. J Immunol (1982) $128: 2374-6$.

12. Mold C, Nakayama S, Holzer TJ, Gewurz H, Du Clos TW. C-reactive protein is protective against Streptococcus pneumoniae infection in mice. J Exp Med (1981) 154:1703-8. doi: 10.1084/jem.154.5.1703

13. Suresh MV, Singh SK, Ferguson DAJr, Agrawal A. Human C-reactive protein protects mice from Streptococcus pneumoniae infection without binding to pneumococcal C-polysaccharide. J Immunol (2007) 178:1158-63. doi: 10.4049/jimmunol.178.2.1158

14. Gang TB, Hammond DJJr, Singh SK, Ferguson DAJr, Mishra VK, Agrawal A, et al. The phosphocholine-binding pocket on C-reactive protein is necessary for initial protection of mice against pneumococcal infection. J Biol Chem (2012) 287:43116-25. doi: 10.1074/jbc.M112.427310

15. Gang TB, Hanley GA, Agrawal A. C-reactive protein protects mice against pneumococcal infection via both phosphocholine-dependent and phosphocholine-independent mechanisms. Infect Immun (2015) 83:184552. doi: 10.1128/IAI.03058-14

16. Nakayama S, Gewurz H, Holzer T, Du Clos TW, Mold C. The role of the spleen in the protective effect of C-reactive protein in Streptococcus pneumoniae infection. Clin Exp Immunol (1983) 54:319-26.

17. Szalai AJ, Briles DE, Volanakis JE. Role of complement in C-reactive proteinmediated protection of mice from Streptococcus pneumoniae. Infect Immun (1996) 64:4850-3. doi: 10.1128/IAI.64.11.4850-4853.1996

18. Mold C, Rodic-Polic B, Du Clos TW. Protection from Streptococcus pneumoniae infection by $\mathrm{C}$-reactive protein and natural antibody requires complement but not Fc $\gamma$ receptors. J Immunol (2002) 168:6375-81. doi: 10.4049/jimmunol.168.12.6375

19. Shrive AK, Cheetham GMT, Holden D, Myles DAA, Turnell WG, Volanakis JE, et al. Three-dimensional structure of human C-reactive protein. Nat Struct Biol (1996) 3:346-54. doi: 10.1038/nsb0496-346

20. Thompson D, Pepys MB, Wood SP. The physiological structure of human C-reactive protein and its complex with phosphocholine. Structure (1999) 7:169-77. doi: 10.1016/S0969-2126(99)80023-9

21. Ngwa DN, Singh SK, Gang TB, Agrawal A. Treatment of pneumococcal infection by using engineered human C-reactive protein in a mouse model. Front Immunol (2020) 11:586669. doi: 10.3389/fimmu.2020.586669

22. Hammond DJJr, Singh SK, Thompson JA, Beeler BW, Rusinol AE, Pangburn MK, et al. Identification of acidic pH-dependent ligands of pentameric C-reactive protein. J Biol Chem (2010) 285:36235-44. doi: 10.1074/jbc.M110.142026

23. Singh SK, Thirumalai A, Hammond DJJr, Pangburn MK, Mishra VK, Johnson DA, et al. Exposing a hidden functional site of C-reactive protein by sitedirected mutagenesis. J Biol Chem (2012) 287:3550-8. doi: 10.1074/ jbc.M111.310011

24. Singh SK, Thirumalai A, Pathak A, Ngwa DN, Agrawal A. Functional transformation of C-reactive protein by hydrogen peroxide. J Biol Chem (2017) 292:3129-36. doi: 10.1074/jbc.M116.773176

25. Pathak A, Singh SK, Thewke DP, Agrawal A. Conformationally altered C-reactive protein capable of binding to atherogenic lipoproteins reduces atherosclerosis. Front Immunol (2020) 11:1780. doi: 10.3389/fimmu.2020.01780

26. Zuckerman JM. The newer macrolides: Azithromycin and clarithromycin. Infect Dis Clin North Am (2000) 14:449-62. doi: 10.1016/S0891-5520(05)70257-9

27. Tessier PR, Kim M-K, Zhou W, Xuan D, Li C, Ye M, et al. Pharmacodynamic assessment of clarithromycin in a murine model of pneumococcal pneumonia. Antimicrob Agents Chemother (2002) 46:1425-34. doi: 10.1128/ AAC.46.5.1425-1434.2002
28. Alvarez-Elcoro S, Enzler MJ. The macrolides: erythromycin, clarithromycin and azithromycin. Mayo Clin Proc (1999) 74:613-34. doi: 10.4065/74.6.613

29. Kakegawa T, Hirose S. Mode of inhibition of protein synthesis by metabolites of clarithromycin. Chemotherapy (1990) 38:317-23. doi: 10.11250/ chemotherapy1953.38.317

30. Yanagihara K, Tomono K, Kuroki M, Kaneko Y, Sawai T, Ohno H, et al. Intrapulmonary concentrations of inflammatory cytokines in a mouse model of chronic respiratory infection caused by Pseudomonas aeruginosa. Clin Exp Immunol (2000) 122:67-71. doi: 10.1046/j.1365-2249.2000.01343.x

31. Ianaro A, Ialenti A, Maffia P, Sautebin L, Rombolà L, Carnuccio R, et al. Antiinflammatory activity of macrolide antibiotics. J Pharmacol Exp Ther (2000) 292:156-63.

32. Giamarellos-Bourboulis EJ, Adamis T, Laoutaris G, Sabracos L, Koussoulas V , Mouktaroudi $\mathrm{M}$, et al. Immunomodulatory clarithromycin treatment of experimental sepsis and acute pyelonephritis caused by multidrug-resistant Pseudomonas aeruginosa. Antimicrob Agents Chemother (2004) 48:93-9. doi: 10.1128/AAC.48.1.93-99.2004

33. Ramos-Sevillano E, Rodríguez-Sosa C, Cafini F, Giménez MJ, Navarro A, Sevillano D, et al. Cefditoren and ceftriaxone enhance complement-mediated immunity in the presence of specific antibodies against antibiotic-resistant pneumococcal strains. PLoS One (2012) 7:e44135. doi: 10.1371/ journal.pone. 0044135

34. Yuste J, Giménez MJ, Jado I, Fenoll A, Aguilar L, Casal J. Enhanced decrease of blood colony counts by specific anti-pneumococcal antibodies in the presence of sub-inhibitory concentrations of amoxicillin. J Antimicrob Chemother (2001) 48:594-5. doi: 10.1093/jac/48.4.594

35. Majhi A, Adhikary R, Bhattacharyya A, Mahanti S, Bishayi B. Levofloxacinceftriaxone combination attenuates lung inflammation in a mouse model of bacteremic pneumonia caused by multidrug-resistant Streptococcus pneumoniae via inhibition of cytolytic activities of pneumolysin and autolysin. Antimicrob Agents Chemother (2014) 58:5164-80. doi: 10.1128/ AAC.03245-14

36. Martínez JA, Horcajada JP, Almela M, Marco F, Soriano A, García E, et al. Addition of a macrolide to a beta-lactam-based empirical antibiotic regimen is associated with lower in-hospital mortality for patients with bacteremic pneumococcal pneumonia. Clin Infect Dis (2003) 36:389-95. doi: 10.1086/ 367541

37. Waterer GW. Optimal antibiotic treatment in severe pneumococcal pneumonia-time for real answers. Eur J Clin Microbiol Infect Dis (2005) 24:691-2. doi: 10.1007/s10096-005-0019-5

38. Caballero J, Rello J. Combination antibiotic therapy for community-acquired pneumonia. Ann Intensive Care (2011) 1:48. doi: 10.1186/2110-5820-1-48

39. Worthington RJ, Melander C. Combination approaches to combat multidrugresistant bacteria. Trends Biotechnol (2013) 31:177-84. doi: 10.1016/ j.tibtech.2012.12.006

40. Schneider EK, Reyes-Ortega F, Velkov T, Li J. Antibiotic-non-antibiotic combinations for combating extremely drug-resistant Gram-negative 'superbugs'. Essays Biochem (2017) 61:115-25. doi: 10.1042/EBC20160058

41. Ejim L, Farha M, Falconer S, Wildenhain J, Coombes B, Tyers M, et al. Combinations of antibiotics and nonantibiotic drugs enhance antimicrobial efficacy. Nat Chem Biol (2011) 7:348-50. doi: 10.1038/nchembio.559

Conflict of Interest: The authors declare that the research was conducted in the absence of any commercial or financial relationships that could be construed as a potential conflict of interest.

Copyright (c) $2021 \mathrm{Ngwa}$, Singh and Agrawal. This is an open-access article distributed under the terms of the Creative Commons Attribution License (CC BY). The use, distribution or reproduction in other forums is permitted, provided the original author(s) and the copyright owner(s) are credited and that the original publication in this journal is cited, in accordance with accepted academic practice. No use, distribution or reproduction is permitted which does not comply with these terms. 